\title{
Front Matter: Volume 9302
}

, "Front Matter: Volume 9302," Proc. SPIE 9302, International Conference on Experimental Mechanics 2014, 930201 (11 March 2015); doi:

10.1117/12.2190461

SPIE Event: International Conference on Experimental Mechanics 2014, 2014, Singapore, Singapore 


\title{
PROCEEDINGS OF SPIE
}

\section{International Conference on Experimental Mechanics 2014}

\author{
Chenggen Quan \\ Kemao Qian \\ Anand Asundi \\ Fook Siong Chau \\ Editors
}

\section{5-17 November 2014 \\ Singapore, Singapore}

Co-organized by

Optics and Photonics Society of Singapore (Singapore)

Theoretical and Applied Mechanics Society (Singapore)

Supported by

National University of Singapore (Singapore) • Nanyang Technological University (Singapore) Asian Committee for Experimental Mechanics • Chinese Society of Experimental Mechanics (China) • Korean Society of Mechanical Engineers (Korea, Republic of) • The Japanese Society for Experimental Mechanics (Japan)

Published by

SPIE 
The papers included in this volume were part of the technical conference cited on the cover and title page. Papers were selected and subject to review by the editors and conference program committee. Some conference presentations may not be available for publication. The papers published in these proceedings reflect the work and thoughts of the authors and are published herein as submitted. The publisher is not responsible for the validity of the information or for any outcomes resulting from reliance thereon.

Please use the following format to cite material from this book:

Author(s), "Title of Paper," in International Conference on Experimental Mechanics 2014, edited by Chenggen Quan, Kemao Qian, Anand Asundi, Fook Siong Chau, Proceedings of SPIE Vol. 9302 (SPIE, Bellingham, WA, 2015) Article CID Number.

ISSN: 0277-786X

ISBN: 9781628413885

Published by

SPIE

P.O. Box 10, Bellingham, Washington 98227-0010 USA

Telephone +1 3606763290 (Pacific Time) · Fax +1 3606471445

SPIE.org

Copyright (@ 2015, Society of Photo-Optical Instrumentation Engineers.

Copying of material in this book for internal or personal use, or for the internal or personal use of specific clients, beyond the fair use provisions granted by the U.S. Copyright Law is authorized by SPIE subject to payment of copying fees. The Transactional Reporting Service base fee for this volume is $\$ 18.00$ per article (or portion thereof), which should be paid directly to the Copyright Clearance Center (CCC), 222 Rosewood Drive, Danvers, MA 01923. Payment may also be made electronically through CCC Online at copyright.com. Other copying for republication, resale, advertising or promotion, or any form of systematic or multiple reproduction of any material in this book is prohibited except with permission in writing from the publisher. The CCC fee code is 0277-786X/15/\$18.00.

Printed in the United States of America.

Publication of record for individual papers is online in the SPIE Digital Library.

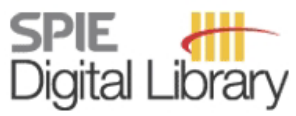

SPIEDigitallibrary.org

Paper Numbering: Proceedings of SPIE follow an e-First publication model, with papers published first online and then in print. Papers are published as they are submitted and meet publication criteria. A unique citation identifier (CID) number is assigned to each article at the time of the first publication. Utilization of CIDs allows articles to be fully citable as soon as they are published online, and connects the same identifier to all online, print, and electronic versions of the publication. SPIE uses a six-digit CID article numbering system in which:

- The first four digits correspond to the SPIE volume number.

- The last two digits indicate publication order within the volume using a Base 36 numbering

system employing both numerals and letters. These two-number sets start with 00, 01, 02, 03, 04, $05,06,07,08,09,0 A, 0 B \ldots$. OZ, followed by 10-1Z, 20-2Z, etc.

The CID Number appears on each page of the manuscript. The complete citation is used on the first page, and an abbreviated version on subsequent pages. 


\title{
Contents
}

\author{
ix Authors \\ xi Conference Committees \\ $\mathrm{xv}$ Introduction
}

ADVANCES IN 3D PROFILE AND SHAPE MEASUREMENT

930207 Phase errors elimination in compact digital holoscope (CDH) based on a reasonable mathematical model [9302-67]

930208 A comparison study of denoising techniques in fringe pattern analysis [9302-220]

930209 Multiview 3D profilometry using resonance-based decomposition and three-phase shift profilometry [9302-251]

\section{SPECKLE AND SPECKLE SHEARING FOR NDT AND STRAIN MEASUREMENT}

9302 OA High temperature deformation measurement based on ultraviolet DIC [9302-213]

$93020 \mathrm{C}$ Shearographic inspections by an interferoscope [9302-101]

9302 OD Speckle shearing interferometer for measuring strain distribution using laser diodes [9302-65]

9302 OE Review of recent developments of spatial phase-shift digital shearography [9302-40]

NDT AND SMART STRUCTURES I

9302 ol Capability enhancement in compact digital holographic microscopy [9302-156]

9302 0J Resonant loading of aircraft secondary structure panels for use with thermoelastic stress analysis and digital image correlation [9302-45]

9302 OK Transmission system of guide-wave for a pipe using a long distance wave guide [9302-31]

9302 OL Quality inspection on electrolytic capacitors using micro-computed tomography [9302-64]

$93020 \mathrm{~N}$ Interpolation method in simple computed tomography scanner [9302-63] 
PHASE RETRIEVAL AND IMAGE PROCESSING

$930200 \quad$ Single-pixel optical imaging with compressed reference intensity patterns [9302-97]

$93020 Q \quad$ Phase retrieval from a single fringe pattern using Teager-Hilbert-Huang transform [9302-182]

9302 OR Nonlinear optical security system with a modified amplitude phase retrieval algorithm [9302-160]

MICRO AND NANO-MECHANICS I

9302 OS Evaluation of crack-healing behavior in $\mathrm{SiN}_{\mathbf{x}} / \mathrm{SiC}$ nanolaminated thin film by microbending test [9302-92]

9302 OV Directional-sensitive differential laser Doppler vibrometry for in-plane motion measurement of specular surface [9302-42]

\section{D TOMOGRAPHY AND SHAPE MEASUREMENT}

9302 OW Fast scanning and quick sampling in computed tomography [9302-178]

$93020 \mathrm{~A} \quad$ A novel one-dimensional phase-shift technique by using crossed fringe for phase measuring deflectometry [9302-257]

9302 OY 3D image reconstruction on x-ray micro-computed tomography [9302-177]

\section{EXPERIMENTAL SOLID MECHANICS II}

930210 Alloy composition dependency of plastic deformation behavior in biaxial compressions of Ti-Nb alloys [9302-72]

930211 Identification of heterogeneous elastic material characteristics by virtual fields method [9302-143]

930215 Experimental investigation on fracture of layered plates [9302-128]

MICRO AND NANO-MECHANICS II

930216 Change and anisotropy of elastic modulus in sheet metals due to plastic deformation [9302-39]

930217 Temperature aspect of degradation of electrochemical double-layer capacitors (EDLC) [9302-123]

930218 A study on notch tip micromechanics in dynamic fracture of polycarbonate [9302-153] 
3D COORDINATE MEASURING AND DIGITAL IMAGE CORRELATION (DIC)

$93021 \mathrm{~A} \quad$ Whole field strain measurement in critical thin adhesive layer of single- and double-sided repaired CFRP panel using DIC [9302-93]

9302 1B Experimental study of leadscrew stresses in-service by digital image correlation [9302-233]

MICROELECTROMECHANICAL SYSTEMS (MEMS) AND APPLICATIONS

$93021 \mathrm{G}$ MEMS-based tunable gratings and their applications (Invited Paper) [9302-204]

$93021 \mathrm{H} \quad$ Broadband vibration energy harvesting using triboelectric mechanism (Invited Paper) [9302-132]

$930211 \quad$ MEMS switchable infrared metamaterial absorber [9302-158]

9302 1J MEMS tunable terahertz metamaterials using out-of-plane mechanisms [9302-174]

\section{COMPOSITES FOR MARINE AND OFFSHORE APPLICATIONS I}

$93021 \mathrm{M} \quad$ Nanofiller reinforcement versus surface treatment effect on the mechanical properties of syntactic foams (Invited Paper) [9302-242]

$93021 \mathrm{~N} \quad$ Non-solution treatment method of carbon nanotubes to prepare strong and tough polymer nanocomposites [9302-239]

930210 Experimental study on behavior of GFRP stiffened panels under compression [9302-68]

9302 IP Failure assessment of aluminum liner based filament-wound hybrid riser subjected to internal hydrostatic pressure [9302-135]

\section{OPTICS AND LASER APPLICATIONS I}

$93021 \mathrm{IR} \quad$ An experimental model for minimizing errors in laser speckle contrast imaging for microcirculation analysis [9302-76]

9302 is Study on non-invasive optical detection of the glucose concentration with scatters [9302-1 17]

$93021 \mathrm{~T} \quad$ Fibre Bragg grating sensors for in-situ measurement of resin pressure in curing composites [9302-215]

9302 IV Dynamic measurement via laser interferometry: crystal growth monitoring and modal parameter analysis [9302-133] 
9302 IW A stress-free model for residual stress assessment using thermoelastic stress analysis [9302-198]

$93021 \mathrm{X}$ Design and experimental investigation about a simulation device for particle impact rock breaking [9302-10]

930212 High-resolution projection moiré and its application in out-of-plane displacement test on large area [9302-211]

\section{COMPOSITES FOR MARINE AND OFFSHORE APPLICATIONS II}

930225 Flexural behavior of epoxy-carbon composite with diffusion effect [9302-218]

930226 Evaluation of seawater exposure on mechanical properties and failure behavior of E-Glass/BMI composite for marine use [9302-210]

\section{OPTICS AND LASER APPLICATIONS II}

930228 Evaluation of expansion algorithm of measurement range suited for 3D shape measurement using two pitches of projected grating with light source-stepping method [9302-235]

930229 Modeling of retardance in ferrofluid with Taguchi-based multiple regression analysis [9302-54]

9302 2B ifringe: a fringe analysis application for mobile smart devices [9302-217]

\section{EXPERIMENTAL SOLID MECHANICS III}

9302 2C Can we use virtual reality tools in the planning of an experiment? [9302-159]

$93022 \mathrm{~F}$ The effect of elastic modulus and friction coefficient on rubber tube sealing performance [9302-144]

\section{FLUID AND HYBRID MECHANICS}

$93022 \mathrm{G} J$-integral evaluation for an interface crack under thermal load using digital image correlation [9302-56]

$93022 \mathrm{H} \quad$ Study about oil displacement efficiency of different position in very high water cut reservoir [9302-43] 
$93022 \mathrm{P} \quad$ Analysis of stress distribution in dry masonry walls using three fringe photoelasticity [9302-181]

9302 2Q Birefringence characterization of injection molded microplates [9302-120]

$93022 \mathrm{R} \quad$ Characterization of friction at three contact pairs by photoelastic isotropic point (IP) [9302-253]

NDT AND SMART STRUCTURES II

$930225 \quad$ In-flight measurements of aircraft propeller deformation by means of an autarkic fast rotating imaging system [9302-185]

9302 2T Pipe inspection system of a pipe by three-modes guide wave using polarized-transverse wave EMATs [9302-22]

$93022 \mathrm{U} \quad$ Study of ultrasonic sensor that is effective for all direction using an electromagnetic force [9302-73]

EXPERIMENTAL SOLID MECHANICS IV

$93022 \mathrm{~V} \quad$ Impact face influence on low velocity impact performance of interply laminated plates [9302-209]

\section{POSTER SESSION}

9302 2X Deformation measurement for a rotating deformable lap based on inverse fringe projection [9302-95]

$93022 Y \quad H i g h-s p e e d$ 3D face measurement based on color speckle projection [9302-51]

$93022 Z$ The design of a low-speed wind tunnel for studying the flow field of insects' flight [9302-98]

930233 On the motion of a falling circular cylinder in flows after water entry [9302-166]

930237 Measurement of thin film adhesion by single cantilever beam method equipped with adjustable jig [9302-214]

930239 Modeling and compensation of flexible modes in 3-DOF H-gantry with decoupling design: a primitive study [9302-246]

9302 3A Reinforced polyethylene/clay nanocomposites: influence of different silane [9302-232]

9302 3E Design and characterization of a silicon piezoresistive three-axial force sensor for microflapping wing MAV applications [9302-163] 
9302 3F Two-dimensional phase unwrapping algorithms for fringe pattern analysis: a comparison study [9302-157]

930231 Silicon wafer microstructure imaging using InfraRed Transport of Intensity Equation [9302-89]

9302 3J Research on inner defect detection of pressure vessels with digital shearography [9302-206]

9302 3K Two-wavelength microscopic speckle interferometry using colour CCD camera [9302-155]

$93023 \mathrm{~L} \quad$ Estimation of stress relaxation time for normal and abnormal breast phantoms using optical technique [9302-134]

$93023 \mathrm{M}$ A new phase error compensation method in digital holographic microscopy [9302-59]

$93023 \mathrm{~N}$ A time-sequential backlight based on a LED collimation module [9302-208]

930230 Multiple reflectors based autocollimator for three-dimensional angle measurement [9302-62]

$93023 Q \quad$ The design and fabrication of an optical diffuser for head-up displays [9302-212]

$93023 R \quad$ White light interferometer with color CCD for 3D-surface profiling of microsystems [9302-152] 


\section{Authors}

Numbers in the index correspond to the last two digits of the six-digit citation identifier (CID) article numbering system used in Proceedings of SPIE. The first four digits reflect the volume number. Base 36 numbering is employed for the last two digits and indicates the order of articles within the volume. Numbers start with 00, 01, 02, 03, 04, 05, 06, 07, 08, 09, 0A, 0B...0Z, followed by 10-1Z, 20-2Z, etc.

Achintha, Mithila, 1W

Adhikari, Achyut, 2Q

Agnihotri, Servesh, 15

Agusanto, Kusuma, OV

Arikawa, Shuichi, 11, 16, 2G

Asai, Tatsuhiko, $2 \mathrm{G}$

Asundi, Anand, 07, 0I, 1P, 1T, 2Q, 3I, 3M

Baek, Dong-Cheon, 17

Baig, lqbal, 2P

Balakrishnan, Deepan, $0 Q$

Banerjee, Arnab, IR

Basu, Sumit, 18

Bing, Shaoxian, $2 \mathrm{H}$

Boden, Fritz, 2S

Bourgade, Thomas, 31

Buerakov, Wassili, OC

Burnett, Ian S., 09

Chai, Gin Boay, 25, 26, 2 V

Chan, Jacob, 2B

Chen, Jubing, $1 Z$

Chen, Li, OA

Chen, Si-Lu, 39

Chen, Ssu-Yu, 1B

Chen, Suli, $1 X$

Chen, Terry Yuan-Fang, 1B

Chen, Wen, 00

Chen, XU, OE

Chen, Xudong, 00

Chen, Xuelong, 3A

Chen, Ye, $1 \mathrm{M}$

Chen, Yi-Cheng, 3Q

Chen, Zhong, $1 T$

Cheng, Cheeyuen, 07

Cheng, Xiaoze, $1 \mathrm{X}$

Chou, Ming-Chieh, $3 Q$

Dhakar, Lokesh, 1H

Dikshit, Vishwesh, IP

Du, Yongzhao, 3l

Dulieu-Barton, Janice M., OJ, IW

Faye, Anshul, 18

Feng, Guoying, 31

Feng, X., 3J

Fu, YU, IV

Fujigaki, Motoharu, 28

Ganapathi, A. S., IT

Ganesh Mahidhar, P. K., 10

Gharib, Fraj, 39

Harada, Y., OS

Häusler, Gerd, OX
Hawong, Jai-Sug, 37

He, X. Y., 3J

Hiraoka, Motoki, OD

Hirayama, Takahiro, $2 \mathrm{U}$

Hisada, Kazuki, 10

Ho, Chong Pei, 1l, 1 J

Howell, Geoffrey, 1W

$\mathrm{Hu}, \mathrm{Xiao}, 1 \mathrm{M}, 1 \mathrm{~N}, 3 \mathrm{~A}$

Ishikawa, Shinichi, 10

Ishitsuka, Yuki, 16

Iwahashi, Yoshihisa, OD

Iwaya, Kazuki, $2 U$

Joshi, Sunil C., $1 T$

Kankeri, Pradeep, 10

Kashfuddoja, Mohammad, lA

Kim, Hyun-Ho, 17

Kobayashi, Makiko, 2T

Kothiyal, Mahendra Prasad, 3K, 3R

Kucaba-Pietal, Anna, 2C

Kumar, A. Senthil, 3E

Lau, Gih-Keong, OV

Lee, Chengkuo, 1H, 1I, 1J

Lee, Chi-Hung, 3N, 3Q

Lee, Jung-Ju, 37

Lee, Soon-Bok, 17

Li, Hongru, 3l

Li, Hua, 33

Li, Xiaona, OE

Li, Yang, $1 \mathrm{X}$

Li, Zhimiao, $2 \mathrm{~F}$

Liao, Chia-Chi, 15

Liao, Min, $2 X$

Lim, Tee Tai, 3E

Lin, Jing-Fung, 29

Lin, Li-Han, 1S

Lin, Wei, 39

Lin, Yu Sheng, 11, $1 \mathrm{~J}$

Liu, Haibo, 30

Liv, Jianhua, $1 \mathrm{X}$

Liu, Jubao, 2F

Liv, Ming, $1 \mathrm{M}$

Liu, Ting, OV

Liu, Yuankun, OX

Lo, Yu-Lung, $1 \mathrm{~S}$

Louk, Andreas C., OY

Lua, Kim Boon, 3E

Lyu, Xujian, 33

M. P., Hariprasad, $2 P$

Ma, Ruoxu, $1 \mathrm{X}$ 
Ma, Shih-Hsin, 3N

Ma, Yun, $2 Z$

Maheshwari, Muneesh, IP, IT

Manikandan, Periyasamy, 2V

Matsumoto, Kenshi, OK

Miao, Hong, 1V, $1 \mathrm{Z}$

Müller, Erik, OC

Murata, Yorinobu, 28

Murayama, Riichi, OK, 2T, 2U

Nakatani, M., OS

Nandigana, Krishna Mohan, 3K, 3R

New, T. H., 33

Ning, Jian-guo, $2 Z$

Olesch, Evelyn, OX

Oshida, Yoshihiro, OD

Parameswaran, Venkitanarayanan, 15, 18

Pitchappa, Prakash, 11, 1J

Prakash, S. Suriya, 10

Pramanik, Manojit, 3K, 3R

Pratama, I. B. G. Putra, OL

Qian, Kemao, 08, 2B

Qian, You, 11

Qiao, Dayong, $1 \mathrm{G}$

QU, Weijuan, 07, 0I, 3F, 3M

Quan, C., OQ, OR

Quinn, S., 0J

Ramesh, K., 2P

Ramij, M., 1A, 10

Ren, Fushen, 1X, 2F

Robinson, Andrew F., IW

Roy, Sunanda, iN

Sakaguchi, Toshimasa, 28

Saporoschski, Juri, OC

Sato, Yuya, 11

Schuth, Michael, OC

Seah, Leong Keey, 25, 26

Seng, Ong Lin, IP

Sheu, Jer-Jia, 29

Shimizu, Ichiro, 10

Shin, Dong-Kil, 37

Shiokawa, Kunio, $2 \mathrm{G}$

Simha, K. R. Y., 2R

Singh, Navab, 11

Stasicki, Boleslaw, 25

Su, Ang, 30

Su, Xianyu, OX, $2 Y$

Sujatha, N., IR, $3 \mathrm{~L}$

Sun, Jianfei, OA

Suparta, Gede B., OL, OW, ON, OY

Surendra, K. V. N., 2R

Szczerba, Piotr, 2C

Szumski, Marek, 2C

Tada, Naoya, 10

Tai, An-Chin, 3N

Takemoto, Yoshito, 10

Tang, Hui, 33

Tay, C. J., OQ, OR

Tay, F. E. H., $1 \mathrm{H}$

Teo, Chek Sing, 39

Teo, Josias Yi Si, 2B
Tian, Ch. P., 3J

Tian, Yan, $2 \mathrm{H}$

Tjin, Swee Chuan, IT

Tonoya, Y., OS

Truong, Van Tien, 3E

Udayakumar, K., 3L

Upputuri, Paul Kumar, 3K, 3R

Ushitani, Kenji, OK

Vössing, Frank, OC

Wang, Baojin, $1 \mathrm{X}$

Wang, Y., OR

Wang, Yonghong, OA

Wang, Zhaomin, 07, OI, 3F, 3M

Wang, Zhiying, 25, 26

Watanabe, Yasuaki, $2 \mathrm{G}$

Waugh, Rachael C., OJ

Wei, Zhaoyu, 33

Wen, Yongfu, 07, 0l, 3F, 3M

Weng, Jie, 2T

Wiguna, Gede A., ON

Woolford, Stuart, 09

Wu, Jyh-Shyang, 29

Wu, Kun, OV

Xie, Xin, OE

Xiong, Chen, $1 \mathrm{Z}$

$X U$, Siyuan, $2 F$

Xue, Junpeng, $2 Y$

Yamane, Hiroto, 2G

Yang, Chong, IV

Yang, Fang, Ol, 3F, 3M

Yang, Lianxiang, $\mathrm{OA}, \mathrm{OE}$

Yang, Zheng, OX

Yao, Jun, $1 \mathrm{Z}$

Yeo, Khoon Seng, 3E

Yin, Ming, 3A

Yoneyama, Satoru, 11, 16, 2G

Yu, Qifeng, 30

YU, Yiting, $1 G$

Yuan, Ling, OV

Yuan, Weizheng, $1 G$

Zhang, Hao, OA

Zhang, Liying, 1M, 3A

Zhang, Peng-fei, $2 Z$

Zhang, Ping, IV

Zhang, Qican, 2X, $2 Y$

Zhang, Wei, 3E

Zhao, Hong-yan, $2 Z$

Zhao, Jing, IV

Zhao, Ming, 08

Zhao, Yian, 25, 26

Zhong, Yihua, $2 \mathrm{H}$

Zhou, Guangya, 3E

Zhou, H. H., 3J

Zhou, Shouhuan, 31

Zhu, Changchun, IV

Zhu, Chuangui, OV

Zuo, Chao, 31 


\title{
Conference Committees
}

\author{
Conference Chairs
}

Anand Asundi, Nanyang Technological University (Singapore) Fook Siong Chau, National University of Singapore (Singapore)

Conference Program Committee

Siew-Lok Toh, National University of Singapore (Singapore) Cho Jui Tay, National University of Singapore (Singapore) Chenggen Quan, National University of Singapore (Singapore) Kemao Qian, Nanyang Technological University (Singapore) Yu Fu, Nanyang Technological University (Singapore)

International Advisory Committee

H. Aben (Estonia)

J. D. Achenbach (United States)

S. K. Babu (Singapore)

Janice (Dulieu-) Barton (United Kingdom)

W. Bonfield (United Kingdom)

F. Bremand (France)

H. A. Bruck (United States)

M. Y. Chen (China)

F. P. Chiang (United States)

D. Djurdjanovic (United States)

H. J. Gao (United States)

R. S. Geng (China)

K. T. V. Grattan (United Kingdom)

W. Herzog (Canada)

X. T. Hu (China)

A. N. B. Ibrahim (Malaysia)

K. S. Kim (United States)

G. B. King (United States)
K. Patorski (Poland)

M. Pearcy (Australia)

B. Raj (India)

P. Rastogi (Switzerland)

R. O. Ritchie (United States)

A. Rosakis (United States)

R. E. Rowlands (United States)

S. Sakai (Japan)

M. Sato (Japan)

C. A. Sciammarella (United States)

C. Shakher (India)

W. N. Sharpe, Jr. (United States)

R. Silver (United States)

M. Takeda (Japan)

M. Tanaka (Japan)

H. V. Tippur (United States)

H. Tiziani (Germany)

M. Tuttle (United States) 

J. S. Leng (China)
T. Vorburger (United States)
O. Lokberg (Norway)
K. Worden (United Kingdom)
B. Michel (Germany)
X. F. Xu (United States)
N. Ooka (Japan)
S. L. Zhang (China)
W. Osten (Germany)
X. Zhang (United States)

Members of the Asian Committee on Experimental Mechanics (ACEM)

\section{P. Almoro (Philippines) \\ K. Arakawa (Japan)}

A. Asundi (Singapore)

M. R. Ayatollahi (Iran)

T. Y. Chen (Taiwan)

S. T. Dinh (Vietnam)

D. Goldar (India)

J. S. Hawong (Korea, Republic of)

Y. Y. Hung (Hong Kong)

A. N. Ibrahim (Malaysia)

A. Kato (Japan)

J. Kokaj (Kuwait)

R. Kunnemeyer (New Zealand)

Alan. K. T. Lau (Hong Kong)

O. S. Lee (Korea, Republic of)

S. B. Lee (Korea, Republic of)

Y. L. Lo (Taiwan)

Y. W. Mai (Australia)

A. Y. Mohammad (Egypt)

Y. Morimoto (Japan)
Y. Nakai (Japan)

L. Parnas (Turkey)

V. H. Pham (Vietnam)

P. Pinit (Thailand)

K. Qian (Singapore)

K. Ramesh (India)

M. M. Ratnam (Malaysia)

S. Sardy (Indonesia)

K. Shankar (Australia)

S. Sirisoonthorn (Thailand)

X. Y. Su (China)

S. B. Suparta (Indonesia)

C. J. Tay (Singapore)

S. L. Toh (Singapore)

P. Venkit (India)

W. S. Wan Abdullah (Malaysia)

W. C. Wang (Taiwan)

J. Widjaja (Thailand)

X. P. Wu (China)

H. M. Xie (China)

Session Chairs

$\mathrm{KN}-1$

Keynote Lecture 1

A. Asundi, Nanyang Technological University (Singapore)

$\mathrm{KN}-2$

Keynote Lecture 2

F. S. Chau, National University of Singapore (Singapore) 
$\mathrm{KN}-3$

Special S111

Special S112

Special S113

$S 121$

$S 122$

$S 123$

$S 131$

$\$ 132$

$\$ 133$

Special S21 1

Special S212

Special S213

S221

S222

S223

S231
Keynote Lecture 3

S. L. Toh, National University of Singapore (Singapore)

Advances in 3D Profile and Shape Measurement

L. J. Chen, Singapore University of Technology and Design (Singapore)

Speckle and Speckle Shearing for NDT and Strain Measurement

L. X. Yang, Auckland University (New Zealand)

Dynamic Behavior of Materials and Structures and Vibration Analysis

J. S. Dhupia, Nanyang Technological University (Singapore)

NDT and Smart Structures I

J. M. Dulieu-Barton, University of Southampton (United Kingdom)

Phase Retrieval and Image Processing

K. M. Qian, Nanyang Technological University (Singapore)

Micro and Nano-Mechanics I

C. J. Tay, National University of Singapore (Singapore)

3D Tomography and Shape Measurement

L. J. Chen, Singapore University of Technology and Design (Singapore)

Experimental Solid Mechanics II

W. Chen, National University of Singapore (Singapore)

Micro and Nano-Mechanics II

S. B. Lee, Korea Advanced Institute of Science and Technology (Korea, Republic of)

3D Coordinate Measuring and Digital Image Correlation (DIC)

Q. F. Yu, National University of Defense Technology (China)

Microelectromechanical Systems (MEMS) and Application

G. Y. Zhou, National University of Singapore (Singapore)

Composites for Marine and Offshore Applications I

J. Yang, Nanyang Technological University (Singapore)

Optics and Laser Applications I

W. J. Qu, Ngee Ann Polytechnic (Singapore)

Experimental Solid Mechanics I

X. Y. He, Southeast University (China)

Y. Fu, Nanyang Technological University (Singapore)

Composites for Marine and Offshore Applications II

z. Jiang, South China University of Technology (China)

Optics and Laser Applications II

Y. L. Lo, National Cheng Kung University (Taiwan) 
Experimental Solid Mechanics III

W. C. Wang, National Tsing Hua University (Taiwan)

Fluid and Hybrid Mechanics

T. Chen, National Cheng Kung University (Taiwan)

Special S311 Biomechanics

A. Kishen, University of Toronto (Canada)

Special S313 Digital Photoelasticity

S. Yoneyama, Aoyama Gakuin University (Japan)

S321

NDT and Smart Structures II

M. Fujigaki, Wakayama University (Japan)

S323

Experimental Solid Mechanics IV

L. Y. Zhang, Nanyang Technological University (Singapore) 


\section{Introduction}

The International Conference on Experimental Mechanics (ICEM 2014), in conjunction with 13th Asian Conference on Experimental Mechanics (ACEM13), was successfully held 15-17 November 2014, at Holiday Inn Atrium Hotel, Singapore. The conference was attended by 155 delegates from 14 countries.

The conference program included three keynote talks given by eminent experts in their respective fields. Professor Janice M. Dulieu-Barton of Southampton University (United Kingdom) delivered a lecture entitled "Imaging Techniques for Performance Assessments of Composite Structures based on Combining Thermoelastic Stress Analysis and Digital Image Correlation." Professor Qifeng Yu of National University of Defense Technology (China) presented the second keynote lecture, "Displacement-relay Videometric Methods for Surface Multiposition Subsidence Surveillance." Professor Anil Kishen of the University of Toronto (Canada) presented the third keynote lecture on "A Biomechanical Understanding of Dentin Hard Tissue."

Apart from the above, 101 papers were presented in 22 oral sessions and 28 papers were presented in 8 poster sessions. The conference covered topics ranging from traditional solid mechanics to fluid mechanics and dynamics, to the more current micro- and nano-mechanics, biomechanics, and smart structures and nondestructive testing (NDT). There were 8 special sessions: 1) Advances in 3D Profile and Shape Measurement; 2) Speckle and Speckle Shearing for NDT and Strain Measurement; 3) Dynamic Behavior of Materials and Structures, Vibration Analysis; 4) 3D Coordinate Measuring and Digital Image Correlation (DIC); 5) Microelectromechanical Systems (MEMS) and Application; 6) Composites for Marine and Offshore Applications; 7) Biomechanics; and 8) Digital Photoelasticity.

We take this opportunity to thank all speakers and authors for contributing to the success of the conference, members of the International Advisory Committee for their assistance and enthusiastic support, the session chairs, our sponsors, and the organizing committee for ensuring the efficient execution of the conference program. 


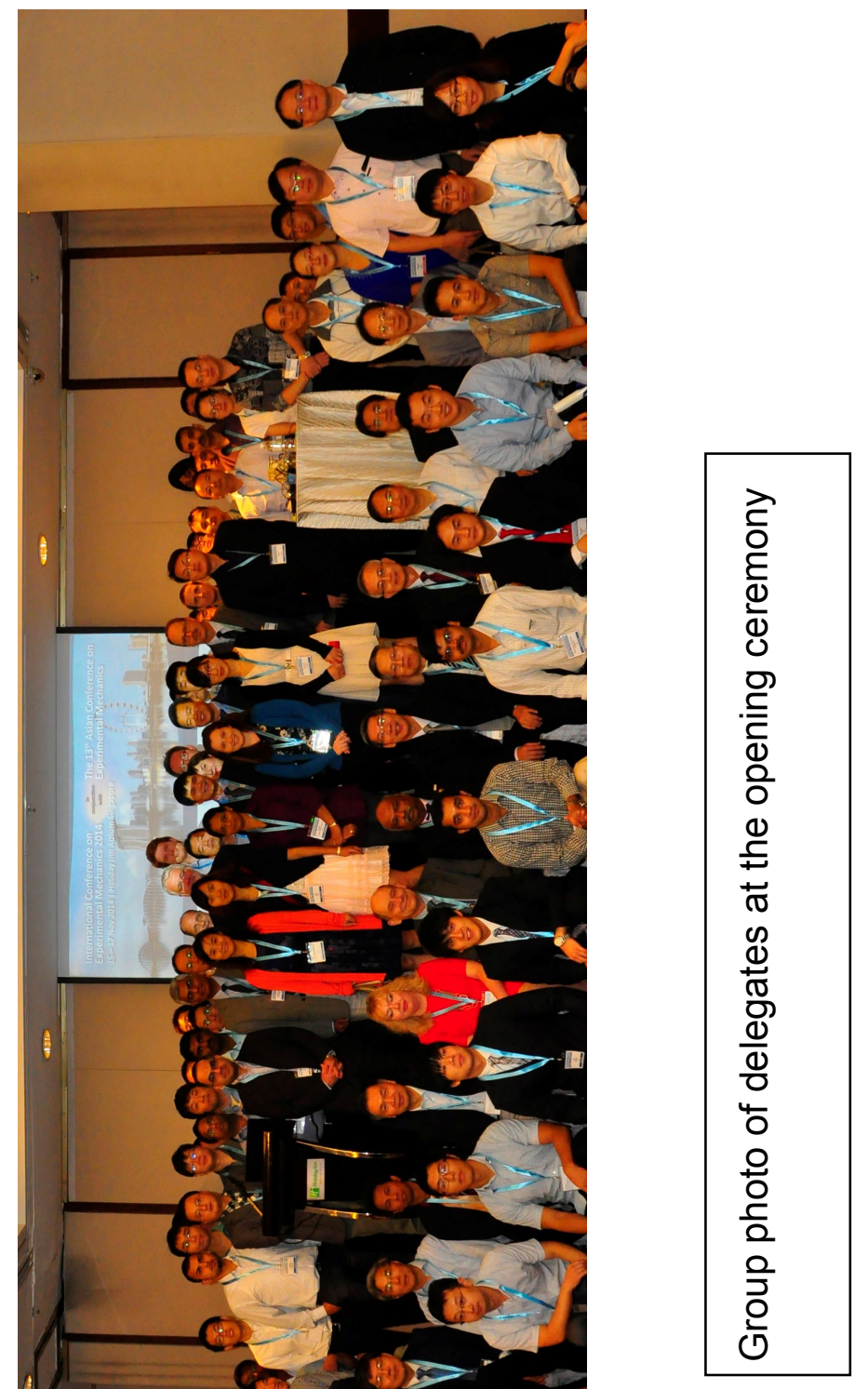

$\mathrm{xvi}$

Proc. of SPIE Vol. 9302 930201-16

Downloaded From: https://www.spiedigitallibrary.org/conference-proceedings-of-spie on 26 Apr 2023 Terms of Use: https://www.spiedigitallibrary.org/terms-of-use 